\title{
A case of IgD myeloma presenting as diffuse osteosclerosis
}

\author{
P K MACCALlUM,* A J FREEMONT, $\dagger$ C G GEARY,* J A LIU YIN* \\ From the University Departments of *Haematology and $\dagger$ Histopathology, Manchester Royal Infirmary
}

SUMMARY A case of IgD myeloma accompanied by diffuse osteosclerosis is reported. A trephine biopsy specimen showed only reticulin fibrosis, but histomorphometric analysis of a full thickness transiliac bone biopsy specimen showed increased trabecular bone mass, with no local deposit of tumour. An excess of bone surfaces were covered by osteoid seams, all of which showed active mineralisation, indicating a relative increase in osteoblastic activity; osteoclasis seemed to be unaffected. It is suggested that the cause of the generalised osteosclerosis might be production of an osteoblast stimulating factor by the myeloma cells.

Osteosclerosis is a rare complication of multiple myeloma with an estimated incidence of up to $3 \% .^{\prime}$ In most cases, however, there are isolated sclerotic deposits or mixed sclerotic and lytic lesions ${ }^{23}$ rather than diffuse osteosclerosis. A review of published data ${ }^{4}$ showed only one case of osteosclerosis in a patient with IgD myeloma, although it is unclear whether this was solitary or diffuse. We report a case of IgD myeloma associated with generalised osteosclerosis which resulted from excessive osteoblastic activity, and we postulate that this was caused by the presence of an osteoblast stimulating factor secreted by the myeloma cells.

\section{Case report}

A 40 year old man, who had been exposed to intermittent industrial radiation for the previous 11 years, was first seen in September 1984 with a short history of lethargy. On examination the spleen extended $3 \mathrm{~cm}$ below the costal margin. The blood count showed a haemoglobin concentration of $77 \mathrm{~g} / 1$, a white cell count of $9 \cdot 1 \times 10^{9} / 1$ (neutrophils $47 \%$, lymphocytes $18 \%$, monocytes $8 \%$, eosinophils $3 \%$, metamyelocytes $6 \%$, myelocytes $12 \%$, promyelocytes $2 \%$, blasts $4 \%$ ), and a platelet count of $130 \times 19^{9} / 1$. The blood film showed a leucoerythroblastic picture and rouleaux formation. An attempted bone marrow aspiration produced a dry tap and a trephine biopsy specimen showed increased reticulin. Idiopathic myelofibrosis was provisionally diagnosed and the patient was treated with red cell transfusions.

In March 1985 he was referred to this department

Accepted for publication 16 December 1987 with severe bone pain in the pelvic and pectoral girdles. Examination showed two small supraclavicular nodes; splenomegaly was unchanged and there was no evidence of neuropathy. The blood count had not greatly changed. The blood urea concentration was $23.6 \mathrm{mmol} / \mathrm{l}$, serum creatinine $791 \mu \mathrm{mol} / \mathrm{l}$, creatinine clearance $11 \mathrm{ml} /$ minute, serum calcium $2.4 \mathrm{mmol} / 1$, phosphate activity $1.87 \mathrm{mmol} / \mathrm{l}$, alkaline phosphatase activity $329 \mathrm{IU} / 1$ (normal 75-300 IU/l) and urate $0.79 \mu \mathrm{mol} / \mathrm{l}$. The total protein was $88 \mathrm{~g} / \mathrm{l}$, albumin concentration $39 \mathrm{~g} / \mathrm{l}$; immunoglobulin values were IgG $3 \mathrm{~g} / \mathrm{l}, \operatorname{IgA} 0.1 \mathrm{~g} / \mathrm{l}, \operatorname{IgM} 0.2 \mathrm{~g} / 1$ and serum immunoelectrophoresis showed an IgD $\lambda$ paraprotein band at $31 \mathrm{~g} / \mathrm{l}$. The urine contained $19.8 \mathrm{~g} / 24$ hours of free $\lambda$ light chains and a trace of albumin. A skeletal survey showed generalised increase in bone density without lytic lesions or loss of demarcation between cortex and medulla (fig 1). Attempts at bone marrow aspiration were again unsuccessful. A trephine biopsy specimen showed a hypercellular marrow with infiltration by typical and atypical plasma cells which showed cytoplasmic positivity for $\delta$ heavy chains and $\lambda$ light chains on immunocytochemical staining. The appearances were taken to be consistent with a diagnosis of multiple myeloma. There was also a diffuse increase in reticulin (fig 2). A lymph node biopsy specimen showed sheets of plasmacytoid cells, which again on immunocytochemical staining were positive for cytoplasmic IgD $\lambda$. An $8 \mathrm{~mm}$ full thickness transiliac bone biopsy specimen was taken after the patient had been given a single dose of a tetracycline (Ledermycin).

Histomorphometric analysis was performed using a VIDS II semiautomated image analyser on $5 \mu \mathrm{m}$ undecalcified sections of bone fixed in absolute 


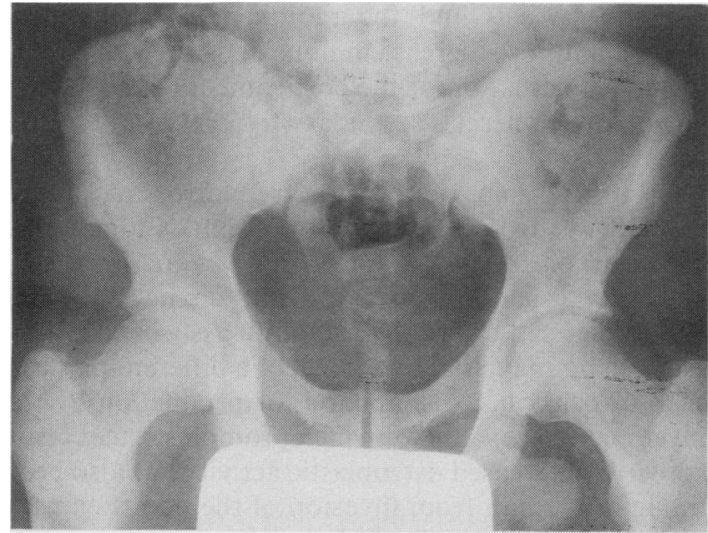

Fig 1 Pelvic $x$-ray picture showing diffuse osteosclerosis.

ethanol, embedded in glycolmethacrylate resin, and stained by von Kossa's method and with toluidine blue. Further unstained sections $(20 \mu \mathrm{m})$ were viewed in ultraviolet light to disclose the distribution of tetracycline. Trabecular bone mass was found to be increased. Trabeculae had a uniform lamellar structure. An excess of mineralised bone surfaces carried osteoid seams of normal thickness and most labelled with tetracycline, indicating active mineralisation. Almost all were covered by plump osteoblasts. Neither the osteoclast count nor the proportion of resorptive surfaces was increased (table, fig 3 ).

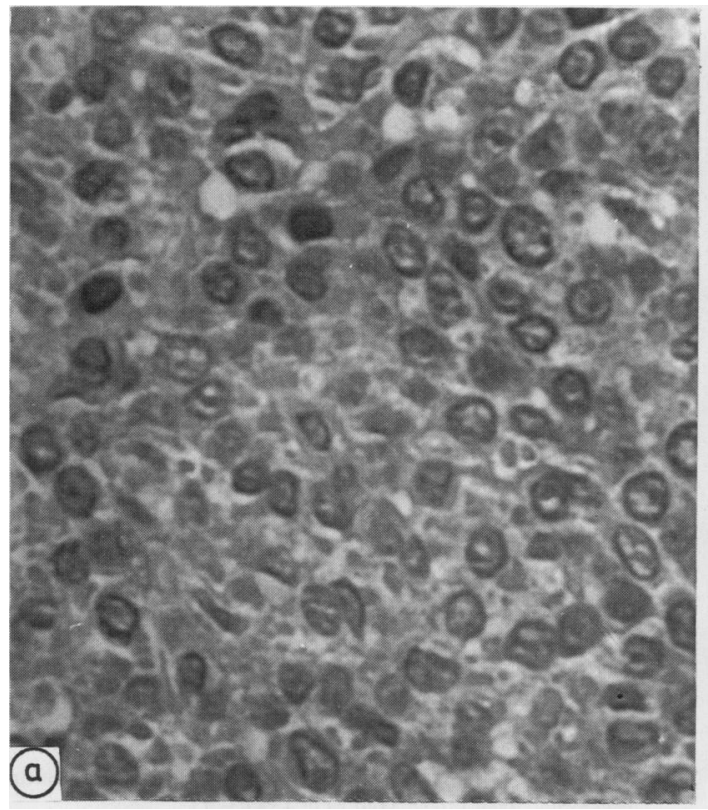

The patient was treated with melphalan and prednisolone with some initial improvement. Four months later there was evidence of progressive extramedullary disease with increasing lymphadenopathy and swelling of the sternoclavicular joints. There was transient clinical and biochemical improvement following treatment with vincristine, doxorubicin, and dexamethasone, but the patient died of septicaemia some 14 months after the initial diagnosis of neoplasia. Necropsy was not carried out.

\section{Discussion}

Multiple myeloma was confirmed in this case by the presence of $\operatorname{IgD} \lambda$ paraprotein in serum and urine and by the trephine biopsy specimen appearances which showed infiltration by atypical plasma cells with a monoclonal phenotype, indicated by their cytoplasmic positivity for $\delta$ heavy chains and $\lambda$ light chains on immunocytochemical staining.

IgD myeloma is an uncommon variety of myeloma that occurs in about $2 \%$ of all cases. ${ }^{4}$ As mentioned above, osteosclerotic myeloma is also extremely rare. Interestingly, published data seem to indicate that both of these forms of myeloma have features which vary from those found in other types of the disease. Patients with IgD myeloma seem to be relatively young, with $65 \%$ of cases less than 60 years old ${ }^{4}$ compared with a mean age of over 60 in patients with myeloma in general. ${ }^{5}$ Extraosseous spread in IgD

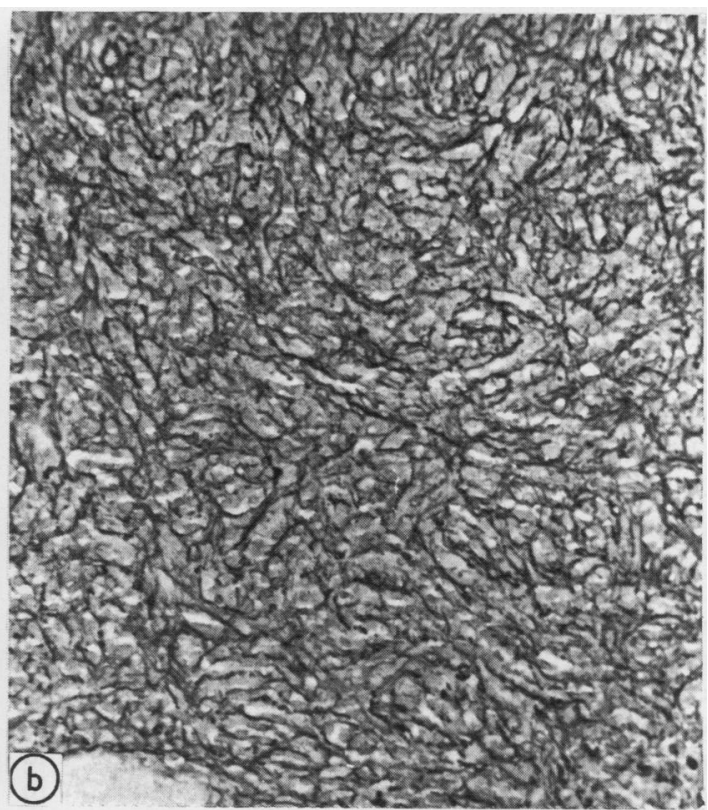

Fig 2 Trephine biopsy specimen: (a) infiltration by pleomorphic primitive cells (Haematoxylin and eosin); (b) diffuse increase in retriculin (Reticulin) 
Table Histomorphometric analysis of transiliac bone biopsy specimen

\begin{tabular}{lll}
\hline & Patients & $\begin{array}{l}\text { Age and sex } \\
\text { matched controls } \\
( \pm I S D)\end{array}$ \\
\hline $\begin{array}{l}\text { Trabecular bone volume } \\
\% \text { Total section area }\end{array}$ & 43 & $19(3)$ \\
$\begin{array}{l}\text { Osteoid covered surfaces } \\
\% \text { of all mineralised bone surfaces }\end{array}$ & 29 & $14(6)$ \\
$\begin{array}{l}\text { Resorptive surfaces } \\
\text { \% of all mineralised bone surfaces }\end{array}$ & 5.3 & $4(1 \cdot 5)$ \\
$\begin{array}{l}\text { Osteoid seams labelling with } \\
\text { Ledermycin }\end{array}$ & 90 & $80(10)$ \\
$\begin{array}{l}\% \text { of all osteoid seams } \\
\text { Osteoclast count } / \mathrm{mm}^{2} \text { of section }\end{array}$ & 0.22 & $0.05(0 \cdot 1)$ \\
\hline
\end{tabular}

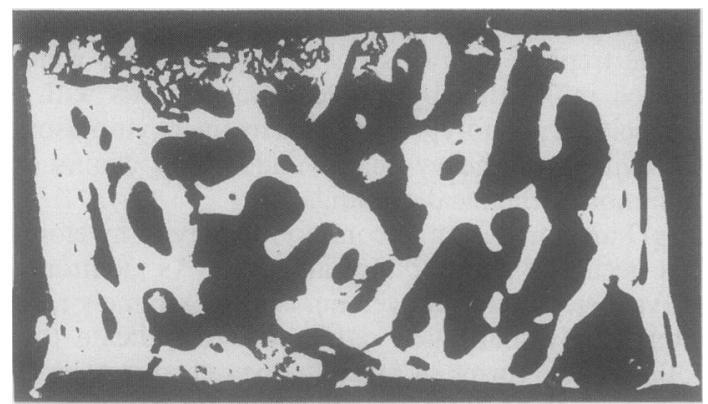

Fig 3 Microradiograph of bone biopsy specimen showing increased bone mass.

myeloma is common and more than $50 \%$ of cases have lymphadenopathy, hepatomegaly, or splenomegaly. Renal impairment is more common than in IgG or IgA myeloma and the prognosis seems to be worse. ${ }^{4}$ In a review of myeloma associated with myelofibrosis, three of 11 cases had IgD myeloma ${ }^{6}$ - an unexpectedly high proportion. Similarly, patients with osteosclerotic lesions tend to be younger and to have a higher incidence of hepatosplenomegaly than other patients with myeloma. ${ }^{2}$ The unusual clinical and pathological features shown in our case, such as young age, lymphadenopathy, splenomegaly, myelofibrosis and short survival, while atypical for myeloma in general, would not be unexpected in osteosclerotic IgD myeloma.

In the common lytic form of myeloma it is recognised that the bone changes result from secretion by the myeloma cells of osteoclast activating factor (OAF), a cytokine with osteoclast stimulating activity, ${ }^{7}$ recently identified as lymphotoxin. ${ }^{8}$ In contrast, the mechanisms by which osteosclerosis is produced in myeloma remain poorly defined. In some cases there may be extensive bone marrow collagen fibrosis accompanied by osteosclerosis ${ }^{9}$; here the picture closely resembles that of the chronic myeloproliferative disorders, and myeloid metaplasia may also be present. ${ }^{6}$ Initially in our case, however, a different pathological mechanism was suggested because there was only moderate reticulin fibrosis and the radiological appearances were of a diffuse increase in bone density, without the loss of demarcation of the corticomedullary junction seen in osteosclerosis secondary to myeloproliferative disease. $^{10}$

In the plasma cell dyscrasia referred to as the POEMS syndrome (the symptom complex comprising polyneuropathy, organomegaly, endocrinopathy, monoclonal gammopathy and skin changes ${ }^{11}$ ) it has been suggested that the commonly associated osteosclerosis ${ }^{1112}$ may arise as a result of a different process, such as osteoclast dysfunction, or production by the myeloma cells of a factor which promotes osteoblastic activity. "Increased osteoblastic activity has also been thought to result from invasion of the periosteum by malignant plasma cells. ${ }^{13}$ High calcitonin concentrations, possibly leading to inhibition of bone resorption, have been described previously in a patient with osteosclerotic myeloma ${ }^{14}$; on the other, production of an osteoblast stimulating factor was postulated as the cause of accelerated bone formation leading to hypocalcaemia in a patient with acute myelomonocytic leukaemia. ${ }^{15}$ In our case, which lacked the cardinal features of the POEMS syndrome, the bone biopsy specimen showed osteosclerosis manifest as excess bone deposition on existing bone surfaces, with apparent dissociation between osteoblastic and osteoclastic activity. The histomorphometric studies seem to indicate that the generalised osteosclerosis seen in this patient resulted from excessive osteoblastic activity, rather than decreased osteoclasis. Although it is impossible to prove that myeloma was responsible for the generalised osteosclerosis, the association in this case, in the absence of another cause, raises the possibility that a humoral osteoblast stimulating factor was produced by the myeloma cells. Were this to be the case, by causing generalised osteoblastic stimulation, it would act in a different way to OAF, which seems to activate local osteoclasts. ${ }^{7}$ Nevertheless, there seems to be an analogy between osteosclerotic and typical myeloma as diffuse bone disturbance, whether osteosclerotic or osteopenic, can occur on its own in both types, although discrete lesions are more common.

\section{References}

1 Case records of the Massachusetts General Hospital. $N$ Engl $J$ Med 1972;287:138-43.

2 Driedger H, Pruzanski W. Plasma cell neoplasia with osteosclerotic lesions. Arch Intern Med 1979;139:892-6.

3 Menu Y, Dhermy D, Brousse N, Grenier Ph, Pallardy G, Nahum H. Myélome Condensant. A propos de trois cas. Revue de la littérature. Ann Radiol 1981;24:265-9.

4 Jancelewicz Z, Takatsuki K, Sugai S, Pruzanski W. IgD multiple myeloma. Arch Intern Med 1975;135:87-93.

5 Kyle RA. Multiple myeloma. Review of 869 cases. Mayo Clin Proc 1975;50:29-40. 
6 Kasimis BS, Yen-Lin R, Neiman RS. Multiple myeloma associated with myelofibrosis. Report of a case and literature review. Oncology 1981;38:369-72.

7 Mundy GR, Raisz LG, Cooper RA, Schechter GP, Salmon SE. Evidence for the secretion of an osteoclast stimulating factor in myeloma. N Engl J Med 1974;291:1041-6.

8 Garrett IR, Durie BGM, Nedwin GE, et al. Production of lymphotoxin, a bone resorbing cytokine, by cultured human myeloma cells. $N$ Engl J Med 1987;317:526-32.

9 Fairley GH, Jackson DC, McDonald P. Osteosclerosis in myelomatosis. Br J Radiol 1964;37:852-5.

10 Ward HP, Block MH. The natural history of agnogenic myeloid metaplasia (AMM) and a critical evaluation of its relationship with the myeloproliferative syndrome. Medicine 1971;50: 357-420.

11 Bardwick PA, Zvaifler NJ, Gill GN, Newman D, Greenway GD, Resnick DL. Plasma cell dyscrasia with polyneuropathy, organomegaly, endocrinopathy, $\mathrm{M}$ protein and skin changes: the POEMS syndrome. Medicine 1980;59:311-22.

12 Case Records of the Massachusetts General Hospital. $N$ Engl $J$ Med 1987;316:606-18.

13 Rodriguez AR, Lutcher CL, Coleman FW. Osteosclerotic myeloma. JAMA 1976;236:1872-4.

14 Rousseau JJ, Franck G, Grisar T, Reznik M, Heynen G, Salmon J. Osteosclerotic myeloma with polyneuropathy and ectopic secretion of calcitonin. Eur J Cancer 1978;14:133-40.

15 Schenkein DP, O'Neill WC, Shapiro J, Miller KB. Accelerated bone formation causing profound hypocalcaemia in acute leukaemia. Ann Intern Med 1986;105:375-8.

Requests for reprints to: Dr P K MacCallum, Registrar, Department of Clinical Haematology, The Royal Infirmary, Manchester M13 9WL, England. 